\title{
Stereoselective Macrocyclization of Peptides in CyClick Chemistry
}

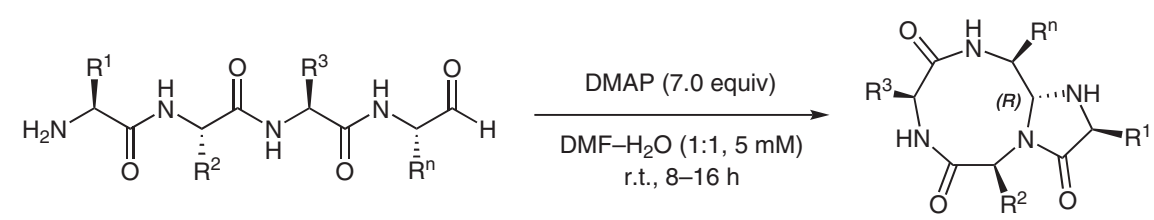

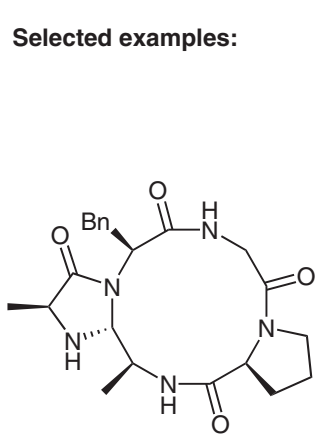

$71 \%$ yield

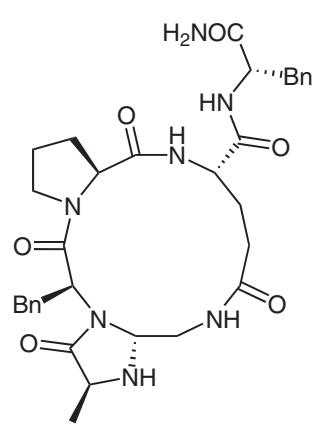

$76 \%$ yield

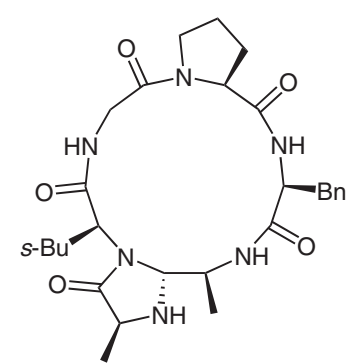

$45 \%$ yield

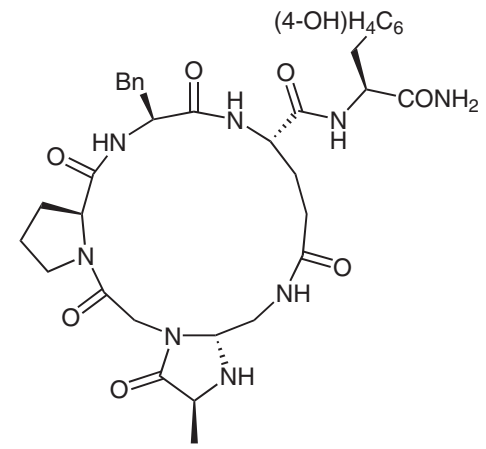

$59 \%$ yield

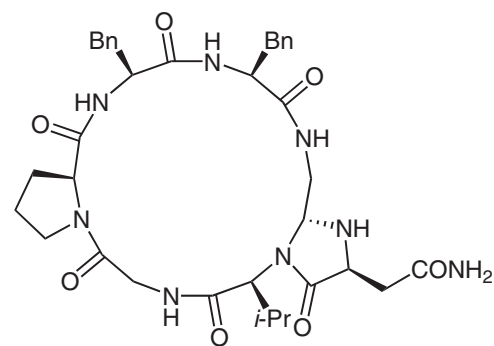

$75 \%$ yield

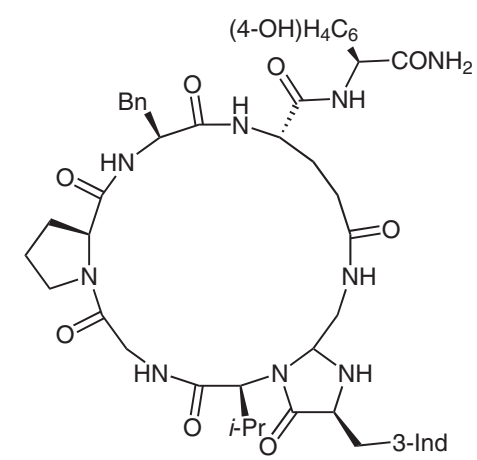

$84 \%$ yield

\section{Key words}

click chemistry

peptides

macrocycles

stereoselectivity

\section{Synfact
oithe Month}

Significance: The pharmaceutical industry's interest in peptide therapeutics is increasing owing to their low toxicities, high specificities towards targeted proteins, and so on. The authors describe a stereoselective macrocyclization of peptides through click chemistry.
Comment: This DMAP-mediated intermolecular cyclization gives the desired cyclic peptides in moderate to high yields without the formation of linear oligopeptides through intramolecular reactions. 